\title{
GERMINAÇÃO IN VITRO E ARMAZENAMENTO DO PÓLEN DE Eugenia involucrata DC (MYRTACEAE) ${ }^{1}$
}

\author{
RODRIGO CEZAR FRANZON² \& MARIA DO CARMO BASSOLS RASEIRA ${ }^{3}$
}

\begin{abstract}
RESUMO - O objetivo do presente trabalho foi o de estabelecer condições adequadas para testes de germinação in vitro do pólen de cerejeira-dorio-grande (Eugenia involucrata DC), bem como verificar a possibilidade de armazená-lo em freezer $\left(-16,5^{\circ} \mathrm{C}\right)$. O pólen foi coletado de flores em estádio de balão e logo após a antese. Os meios de cultura testados foram o meio padrão ( $10 \%$ de açúcar e $1 \%$ de ágar em água destilada) e este acrescido de duas concentrações de $\mathrm{H}_{3} \mathrm{BO}_{3}(0,65 \mathrm{mM} \mathrm{e} 1,3 \mathrm{mM})$. Foram testadas as temperaturas de incubação de 25 e $30^{\circ} \mathrm{C}$. O período de incubação foi de três horas, para todos os tratamentos. A incubação a $25^{\circ} \mathrm{C}$, em meio de cultura-padrão, proporcionou boas médias $(61,4 \%)$ de germinação in vitro. Pólen coletado de flores após a antese apresentou maiores porcentagens de germinação. O boro não influenciou na germinação média do pólen. O pólen de cerejeira-do-rio-grande manteve sua viabilidade (60,0\%) após 90 dias de armazenamento a $-16,5^{\circ} \mathrm{C}$. Entretanto, após 220 e 280 dias, esta foi reduzida para $40,6 \%$ e $24,2 \%$ e, após 530 dias, houve perda total de viabilidade.
\end{abstract}

Termos para Indexação: Myrtaceae, viabilidade de pólen, armazenamento, boro.

\section{IN VITRO POLLEN GERMINATION OF RIO-GRANDE-CHERRY (Eugenia involucrata DC)}

ABSTRACT - The objective of the present work was to determine a suitable medium and conditions for in vitro germination of Rio-Grande-Cherry (Eugenia involucrata DC) pollen. Possibility of storage in freezer $\left(-16,5^{\circ} \mathrm{C}\right)$ was also studied. The pollen was collected from flowers at balloon stage and right after anthesis. The tested media were: the standard ( $10 \%$ sucrose, plus $1 \%$ agar dissolved in distilled water), and the addition of two $\mathrm{H}_{3} \mathrm{Bo}_{3}$ $(0.65 \mathrm{mM}$ and $1.3 \mathrm{mM})$ to this medium. Temperatures of incubation of 25 and $30^{\circ} \mathrm{C}$ were tested. Independent of the treatment the incubation period was three hours. Incubation at $25^{\circ} \mathrm{C}$ in the standard medium provided good germination (61.4\%). Boron did not influence the pollen germination. Pollen collected from flowers right after anthesis showed high germination percentage. The Rio-Grande-Cherry pollen conserved the viability (60.0\%) after 90 days of storage at $-16,5^{\circ} \mathrm{C}$. However, after 220 and 280 days it was reduced to $40.6 \%$ and $24.2 \%$ and, after 530 days, there was total loss of viability. Index Terms: Myrtaceae, pollen viability, storage, boron.

\section{INTRODUÇÃO}

A cerejeira-do-rio-grande (E. involucrata DC.), da família Myrtaceae, é nativa do Sul do Brasil, ocorrendo desde Minas Gerais até o Rio Grande do Sul (Donadio et al., 2002). Esta espécie tem potencial para aproveitamento comercial, e seu fruto pode ser consumido in natura, ou ser utilizado para o processamento na forma de doces, geléias e sucos. Além disso, pode ser utilizada como planta ornamental, tendo em vista sua bonita forma e aparência.

A Embrapa Clima Temperado (CPACT), em Pelotas-RS, mantém um Banco Ativo de Germoplasma de espécies frutíferas nativas do Sul do Brasil. Futuramente, o objetivo é iniciar o melhoramento genético destas espécies. Neste sentido, um dos pontos importantes a ser estudado refere-se ao pólen. Até o momento, para a maioria delas, não são conhecidas as condições adequadas para testes de viabilidade.

A germinação in vitro é o método mais utilizado em testes de viabilidade do pólen em programas de melhoramento genético (Marcellán \& Camadro, 1996). Entretanto, este método é influenciado por diferentes fatores. Existem diferenças entre espécies quanto às condições exigidas para a germinação do pólen, envolvendo, principalmente, os constituintes do meio de cultura, a temperatura e o tempo de incubação. Além disso, a viabilidade do pólen também é influenciada pelo estádio de desenvolvimento da flor, quando da coleta do pólen, e pelas condições de armazenamento (Stanley \& Linskens, 1974).

O meio básico usado nestes testes é constituído de açúcar e de ácido bórico (Miranda \& Clement, 1990), podendo variar ainda a combinação de outros nutrientes (Galletta, 1983). O açúcar promove o equilíbrio osmótico entre o pólen e o meio de germinação, e fornece energia para o desenvolvimento do tubo polínico (Stanley \& Linskens, 1974). Já o boro estimula o crescimento do tubo polínico e diminui a probabilidade de estes se romperem.

Em pesquisa de literatura, para espécies nativas do Sul do Brasil, apenas alguns estudos com pólen de araçazeiro (Psidium cattleyanum) foram encontrados (Hirano \& Nakasone, 1969; Raseira \&
Raseira, 1996)

O objetivo do presente trabalho foi o de estabelecer condições adequadas para testes de viabilidade do pólen de cerejeira-do-riogrande, através da germinação in vitro, bem como verificar a possibilidade de armazenamento em freezer.

\section{MATERIAL E MÉTODOS}

O pólen foi coletado de flores em estádio de balão e de flores logo após a antese, de plantas do Banco Ativo de Germoplasma de fruteiras nativas da Embrapa Clima Temperado - CPACT, no município de Pelotas-RS, na floração de 2003.

As anteras foram destacadas e colocadas para secar em bandejas de papel, à temperatura ambiente $\left(20\right.$ a $\left.25^{\circ} \mathrm{C}\right)$, por três dias, até que o pólen estivesse seco. Parte do pólen foi utilizado nos testes iniciais, e o restante foi armazenado em freezer, à temperatura de $-16,5^{\circ} \mathrm{C}$ $\left( \pm 1,5^{\circ} \mathrm{C}\right)$ e baixa umidade relativa do ar, mantidas em dessecador com sílica como substância higroscópica.

Foram testados os seguintes meios de cultura para germinação in vitro do pólen de cerejeira-do-rio-grande, coletado nas fases de balão e após antese:

1. $10 \%$ de açúcar $+1 \%$ de ágar (testemunha - meio de cultura padrão utilizado em testes de rotina no Laboratório de Melhoramento Genético Vegetal do CPACT);

2. $10 \%$ de açúcar $+1 \%$ de ágar $+0,65 \mathrm{mM}$ de ácido bórico $\left(\mathrm{H}_{3} \mathrm{Bo}_{3}\right)$;

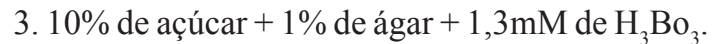

Os elementos constituintes dos meios de cultura foram dissolvidos em água destilada e aquecidos em forno de microondas até a completa dissolução do ágar. O meio de cultura foi distribuído em lâminas preparadas para este fim (lâminas para observação em microscópio óptico, adaptadas com dois anéis de PVC de $21 \mathrm{~mm}$ de diâmetro e $3 \mathrm{~mm}$ de altura), em substituição às lâminas escavadas. $\mathrm{Na}$ avaliação dos resultados, cada anel de PVC, em cada uma das lâminas, representou uma repetição.

\footnotetext{
${ }^{1}$ (Trabalho 120/2005). Recebido: 16/08/2005. Aceito para publicação: 23/02/2006.

${ }^{2}$ Eng $^{\mathrm{o}} \mathrm{Agr}^{\mathrm{o}}$, M.Sc., Aluno do Programa de Pós-Graduação em Agronomia - área de concentração em Fruticultura de Clima Temperado, Universidade Federal de Pelotas, Pelotas-RS. Bolsista CAPES. E-mail: rcfranzon@hotmail.com

${ }^{3}$ Eng $^{\circ}$ Agr ${ }^{\circ}$, Ph.D., Pesquisador Embrapa Clima Temperado - CPACT, Cx.P. 403, CEP: 96001-970, Pelotas, RS. E-mail: bassols@cpact.embrapa.br
} 
O pólen foi aspergido sobre o meio de cultura, e as lâminas foram colocadas em câmara úmida simulada (placas de Petri com papel absorvente umedecido) e levadas para incubação em estufa tipo BOD, nas temperaturas constantes de 25 ou $30^{\circ} \mathrm{C}$. Decorridas três horas de incubação, na ausência de luz, foi realizada a contagem da porcentagem de grãos de pólen germinados, sob microscópio óptico binocular, considerando-se germinados aqueles que apresentavam o comprimento do tubo polínico igual ou superior ao diâmetro do próprio grão de pólen. Foi contado um total de 100 grãos de pólen por repetição.

O delineamento estatístico foi o completamente casualizado, em arranjo fatorial $2 \times 3 \times 2$, sendo dois estágios de desenvolvimento das flores (balão e após antese) no momento da coleta do pólen, três meios de cultura e duas temperaturas de incubação $\left(25\right.$ e $\left.30^{\circ} \mathrm{C}\right)$, com quatro repetições. Os dados foram submetidos à análise de variância e as médias comparadas pelo teste de Duncan $(\mathrm{p}=0,05)$. Para a análise, os dados de porcentagem foram transformados para $\operatorname{arc}-\operatorname{sen}(\sqrt{\mathrm{x} / 100})$.

\section{RESULTADOS E DISCUSSÃO}

Nos testes iniciais, a porcentagem de germinação in vitro de pólen de cerejeira-do-rio-grande coletado de flores após a antese foi maior em relação àquele coletado de flores em estádio de balão (Tabela 1). A germinação média do pólen não diferiu nos diferentes meios de cultura e temperaturas de incubação testados. Não houve interação significativa entre os diferentes fatores estudados.

Após três horas de incubação, o comprimento dos tubos polínicos apresentou mais de 30 vezes o diâmetro do grão de pólen, e a porcentagem média de germinação foi alta $(58,3 \%)$, indicando que esse período é suficiente para testar a viabilidade de pólen desta espécie através da germinação in vitro, uma vez que se considera germinado aquele que apresentar tubo polínico igual ou superior ao seu próprio diâmetro.

TABELA 1 - Porcentagem de germinação in vitro de pólen de cerejeirado-rio-grande, coletado em dois estádios de desenvolvimento da flor.

\begin{tabular}{cc}
\hline Origem do pólen & Médias de germinação* (\%) \\
\hline Flor em estádio de balão & $46,7 \mathrm{~b}^{1}$ \\
Flor após antese & $69,5 \mathrm{a}$ \\
\hline Meio de cultura & $\mathrm{ns}$ \\
\hline $10 \mathrm{~g}$ açúcar & 61,4 \\
$10 \mathrm{~g}$ açúcar $+0,65 \mathrm{mM} \mathrm{H}_{3} \mathrm{Bo}_{3}$ & 57,7 \\
$10 \mathrm{~g}$ açúcar $+1,3 \mathrm{mM} \mathrm{H}_{3} \mathrm{Bo}_{3}$ & 55,9 \\
\hline Temperatura de incubação & $\mathrm{ns}$ \\
\hline $25^{\circ} \mathrm{C}$ & 59,7 \\
$30^{\circ} \mathrm{C}$ & 57,0 \\
\hline Média geral & $58,3 \%$ \\
\hline Coeficiente de variação & $8,47 \%$ \\
\hline
\end{tabular}

${ }^{1}$ médias seguidas por letras distintas diferem entre si, pelo teste de Duncan $(\mathrm{p}=0,05) ; \mathrm{ns}=$ não significativo pelo teste de Duncan $(\mathrm{p}=0,05) ; *$ avaliado após três horas de incubação, na ausência de luz.
Entretanto, períodos de incubação maiores, desde quatro até 13 horas de incubação, foram observados para o pólen de araçazeiro (Hirano \& Nakasone, 1969; Teaotia et al., 1970; Raseira \& Raseira, 1996). Avaliando o pólen de duas cultivares de macieira, Nunes et al. (2001) observaram que duas horas de incubação não foram suficientes para germinação in vitro, sendo necessário um período de cinco horas. Estas referências confirmam que o tempo de incubação necessário para iniciar a germinação in vitro varia de acordo com a espécie, e até mesmo entre cultivares da mesma espécie.

Não houve diferenças entre as porcentagens de germinação nas temperaturas de incubação de 25 e $30^{\circ} \mathrm{C}$, indicando que ambas podem ser utilizadas para testes de germinação in vitro de pólen de cerejeira-do-rio-grande.

Temperaturas de incubação em torno de $25^{\circ} \mathrm{C}$ são citadas em literatura para diversas espécies. Thompson \& Batjer (1950) usaram $24^{\circ} \mathrm{C}$ para pólen de ameixeira, pessegueiro, damasqueiro, cerejeira européia, pereira e macieira. Loupassaki et al. (1997) afirmam que $25^{\circ} \mathrm{C}$ é a ideal para germinação de pólen de abacateiro, e Nunes et al. (2001) utilizaram esta mesma temperatura para macieira.

O pólen de cerejeira-do-rio-grande manteve a viabilidade $(60 \%$ de germinação média) após 90 dias de armazenamento a $-16,5^{\circ} \mathrm{C}$ (Tabela 2). Entretanto, após 220 e 280 dias, a porcentagem de germinação reduziuse para 40,6\% e 24,2\%, respectivamente, e, após 530 dias, houve perda total da viabilidade. Novamente a adição de $\mathrm{H}_{3} \mathrm{Bo}_{3}$ ao meio de cultura não influenciou na porcentagem de germinação do pólen.

A germinação média de pólen coletado de flores após antese foi maior em relação à de pólen coletado de flores em estádio de balão, em todos os períodos de avaliação, exceto aos 530 dias de armazenamento, onde não houve germinação do pólen (Tabela 2).

A maturação do pólen é um dos estádios de desenvolvimento no ciclo de vida das plantas. A germinação do pólen não ocorre dentro da antera, mas este deve estar pronto para germinar logo após a deiscência da mesma (Lin \& Dickinson, 1984), desde que encontre condições favoráveis. Em programas de melhoramento genético, é fundamental coletar o pólen em estádio adequado de maturação, para que o mesmo mantenha a viabilidade e capacidade de germinar quando for realizada a hibridação.

Diferenças ainda maiores do que as aqui encontradas foram obtidas por Luza \& Polito (1985), em noz inglesa. Pólen coletado de flores um a dois dias antes da antese apresentou $0,6 \%$ de germinação, contra $45,2 \%$ de pólen originário de flores após a antese.

Embora o pólen coletado de flores logo após a antese tenha apresentado maiores porcentagens de germinação, deve-se tomar alguns cuidados durante a coleta do mesmo, para ter a garantia de que o pólen a ser utilizado em hibridações, em programas de melhoramento genético, seja puro, sem contaminação por outras fontes de pólen. Uma alternativa é ensacar as flores ainda em estádio de balão, na planta, utilizando sacos de papel encerado, para evitar que, em caso de chuva, estes se desmanchem. Outra alternativa é coletar ramos com flores em estádio de balão e levá-los para um lugar abrigado, mantendo-os em frascos com água para evitar a desidratação e permitir que as flores abram

TABELA 2 - Porcentagem de germinação in vitro de pólen de cerejeira-do-rio-grande, coletado em dois estádios de desenvolvimento da flor, em diferentes períodos após o armazenamento em freezer $\left(-16,5^{\circ} \mathrm{C}\right)$.

\begin{tabular}{|c|c|c|c|}
\hline \multirow{3}{*}{ Períodos de armazenamento (dias) } & \multicolumn{3}{|c|}{ Médias de germinação $(\%)^{1} *$} \\
\hline & \multicolumn{2}{|c|}{ Origem do pólen } & \multirow[b]{2}{*}{ Média } \\
\hline & Flor após antese & Flor em estádio de balão & \\
\hline 00 & 70,9 a $\mathrm{A}$ & 48,0 a $B$ & $59,5 \mathrm{a}$ \\
\hline 90 & 68,6 a $\mathrm{A}$ & 51,3 a B & $60,0 \mathrm{a}$ \\
\hline 220 & $43,0 \mathrm{~b} \mathrm{~A}$ & 38,2 b B & $40,6 \mathrm{~b}$ \\
\hline 280 & $28,7 \mathrm{c} \mathrm{A}$ & 19,7 c B & $24,2 \mathrm{c}$ \\
\hline 530 & $0,0 \mathrm{~d} A$ & $0,0 \mathrm{~d} A$ & $0,0 \mathrm{~d}$ \\
\hline Média & $42,2 \mathrm{~A}$ & $31,4 \mathrm{~B}$ & \\
\hline Coeficiente de variação & & $10,14 \%$ & \\
\hline
\end{tabular}


normalmente, procedendo-se então a coleta do pólen.

$\mathrm{O}$ pólen de cerejeira-do-rio-grande manteve sua viabilidade até os 90 dias de armazenamento em freezer $\left(-16,5^{\circ} \mathrm{C}\right)$. Entretanto, a partir dos 220 dias, houve perda significativa de viabilidade. Em programas de melhoramento genético, o armazenamento de pólen é de extrema importância, pois é necessário que este mantenha viabilidade até o momento em que será utilizado em hibridações. A manutenção da capacidade de germinação do pólen depende, além das características intrínsecas da espécie, das condições de armazenamento.

Lee et al. (1981) relatam que a germinação de pólen de diversas cultivares de ameixeira manteve-se por mais de três anos quando armazenado a $-20^{\circ} \mathrm{C}$; entretanto, a $-1^{\circ} \mathrm{C}$, a viabilidade reduziu-se drasticamente antes dos 11 meses de armazenamento. Para o pólen de araçazeiro, Raseira \& Raseira (1996) observaram considerável perda de viabilidade após 21 dias de armazenamento, nas mesmas condições testadas no presente trabalho para cerejeira-do-rio-grande.

\section{CONCLUSÕES}

1. O pólen de cerejeira-do-rio-grande apresentou boa viabilidade, com germinação inicial média de 58,3\%.

2. A viabilidade do pólen de Eugenia involucrata pode ser avaliada adequadamente através da germinação in vitro, em meio de cultura constituído por $10 \%$ de açúcar e $1 \%$ de ágar, dissolvidos em água destilada, três horas após a inoculação, e incubação à temperatura constante de $25^{\circ} \mathrm{C}$

3. O período ideal para coleta de pólen de E. involucrata é logo após a antese.

4. O armazenamento de pólen de E. involucrata pode ser realizado satisfatoriamente por até 220 dias quando mantido em freezer $\left(-16,5^{\circ} \mathrm{C}\right)$. Houve redução significativa depois deste período.

\section{REFERÊNCIAS}

DONADIO, L.C.; MÔRO, F.V.; SERVIDONE, A.A. Frutas Brasileiras. Jaboticabal: Ed. Novos Talentos, 2002. 288p.

GALLETTA, G.J. Pollen and seed management. In: MOORE, J.N.; JANICK, J. (Ed.). Methods in fruit breeding. Indiana: Purdue University Press, 1983. cap.3, p.23-47.
HIRANO, R.T.; NAKASONE, H.Y. Chromosome numbers of ten species and clones in the genus Psidium. Journal of the American Society for Horticultural Science, Mount-Vernon, v.94, n.2, p.83-86, 1969.

LEE, C.L.; BÜNEMANN, G.; HERMANN, S. Long-term storage of plum pollen. Gartenbauwissenschaft, Stuttgart, v.46, p.69-72, 1981.

LIN, J.J.; DICKINSON, D.B. Ability of pollen to germinate prior to anthesis and effect of desiccation on germination. Plant Physiology, Bathesda, v.74, p.746-748, 1984

LOUPASSAKI, M.; VASILAKAKIS, M.; ANDROULAKIS, I. Effect of pre-incubation humidity and temperature treatment on the in vitro germination of avocado pollen grains. Euphytica, Wageningen, v.94, p.247-251, 1997.

LUZA, J.G.; POLITO, V.S. In vitro germination and storage of english walnut pollen. Scientia Horticulturae, Amsterdam, v.27, p.303-316, 1985.

MARCELLÁN, O.N.; CAMADRO, E.L. The viability of asparagus pollen after storage at low temperatures. Scientia Horticulturae, Amsterdam, 67, p.101-104, 1996.

MIRANDA, P.A.; CLEMENT, C.R. Germination and storage of pejibaye (Bactris gasipaes) Palmae pollen. Revista de Biologia Tropical, San Jose, v.38, n.01, p.29-33, 1990.

NUNES, J.C.O.; DANTAS, A.C.M.; PEDROTTI, E.L.; ORTH, A.I.; GUERRA, M.P. Germinação de pólen in vitro e receptividade do estigma em macieira cvs. Fuji e Golden Delicious. Revista Brasileira de Fruticultura, Jaboticabal, v.23, n.1, p.35-39, 2001.

RASEIRA, M. do C.B. e RASEIRA, A. Contribuição ao estudo do araçazeiro, Psidium cattleyanum. Pelotas-RS: EMBRAPA/CPACT, 1996.95p.

STANLEY, R.G.; LINSKENS, H.F. Pollen biochemistry management. Berlin: Springer Verlag, 1974.307p.

TEAOTIA, S.S.; PHOGOT, K.P.S.; SRISVATAVA, V.S. Blosson biology studies in Psidium species. Progressive Horticulture, Uttar Pradesh, v.2, n.3, p.101-112, 1970.

THOMPSON, A.H.; BATJER, L.P. The effect of boron in the germinating medium on pollen germination and pollen tube growth for several deciduous tree fruits. Proceedings of American Society for Horticultural Science, Mount Vernon, v.56, p.227-230, 1950. 